www.jmscr.igmpublication.org

Index Copernicus Value: 79.54

ISSN (e)-2347-176x ISSN (p) 2455-0450

crossrefDOI: https://dx.doi.org/10.18535/jmscr/v7i1.114

\title{
Multicloculated Thymic Cyst Presenting As Mediastinalmass Mimicking Cystic Thymoma- A Case Report
}

\author{
Authors \\ A. Haretha' ${ }^{1}$ K. Ambedkar Raj ${ }^{2}$, V. Sarada ${ }^{3}$ \\ ${ }^{1}$ Postgraduate, ${ }^{2}$ Guide,${ }^{3}$ Head of the Department \\ Department of Pathology, Trichy SRM Medical College and Research Center
}

\section{Introduction}

Thymic cysts are relatively uncommon lesions, accounting for approximately $3 \%$ of all anterior mediastinal masses.

\section{Case Report}

10 yrs old male child admitted with complaints of recurrent episodes of cough, cold \& fever for the past 1 yr. A chest x-ray was taken which incidentally showed a mediastinal mass. Ct scan of chest was done. Superior mediastinal widening was present. Large no enhancing mass lesion measuring $8 \mathrm{~cm} \times 7.3 \mathrm{~cm}$ present in anterior mediastinum causing encasement of major vessels is seen in the mediastinum. Trachea is compressed. Pulmonary artery dilated. Compression of adjacent lung parenchyma was present.

\section{Cytological Findings}

USG guided FNAC of the lesion revealed- $50 \mathrm{ml}$ straw colored fluid which on microscopy shows high cellularity composed of lymphocytes, epithelial cells in a background of eosinophilic proteinaceous material (Figure-1,2). A provisional diagnosis of Thymic cyst /lymphocytic rich thymoma was given. Then, the child was taken up for surgery.

\section{Histopathological Findings}

The specimen submitted to pathology contained multiple cysts, largest cyst measuring $1.5 \times 1 \mathrm{~cm}$ in diameter and smallest cyst measuring $0.5 \times 0.5 \mathrm{~cm}$ in diameter. The specimen on sectioning appears grey brown and was filled with gray brown fluid (Figure-2, 3). Microscopy showed multiple cyst lined by flattened cells. These features were suggestive of multilocular thymic cyst (Figure- 5, $6)$. 


\section{JMSCR Vol||07||Issue||01||Page 669-671||January}

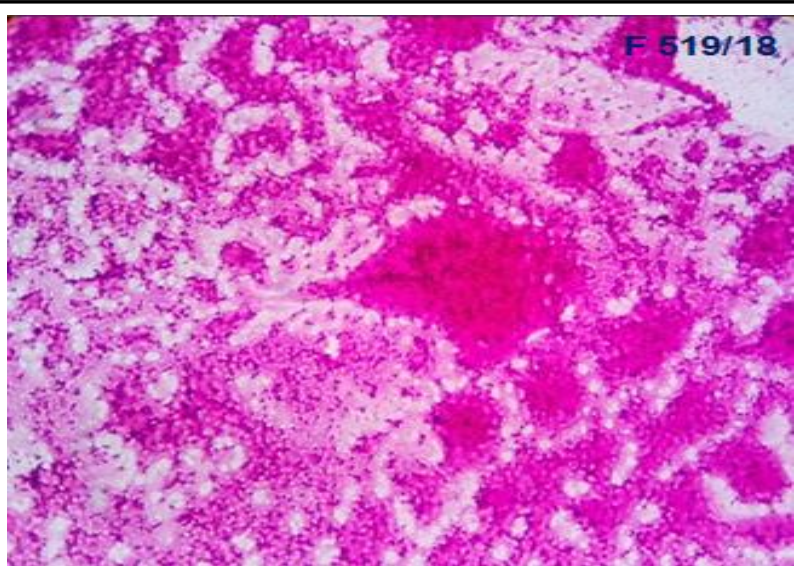

Figure 1: scanner view, $4 \mathrm{X}, \mathrm{H} \& \mathrm{E}$, showing high cellularity composed of lymphocytes and epithelial cells

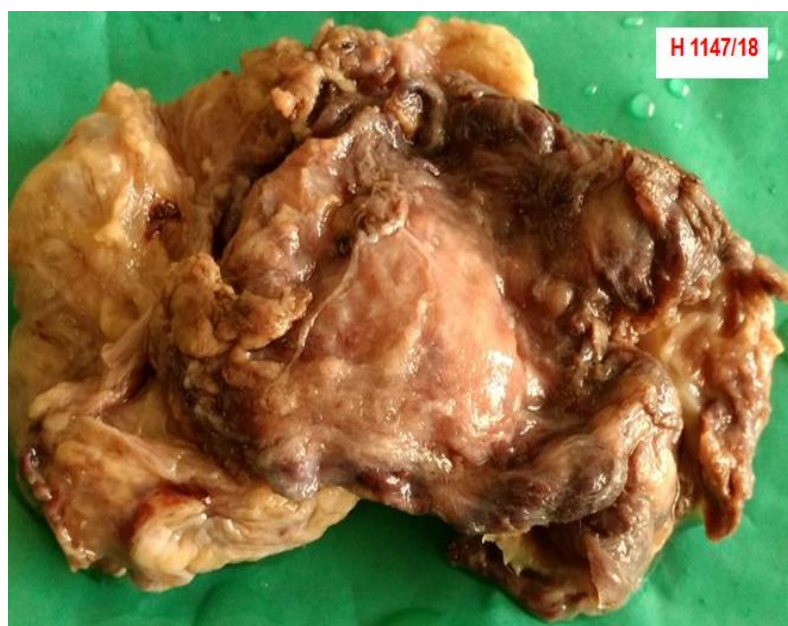

Figure 3: Gross-External surface appears greybrown

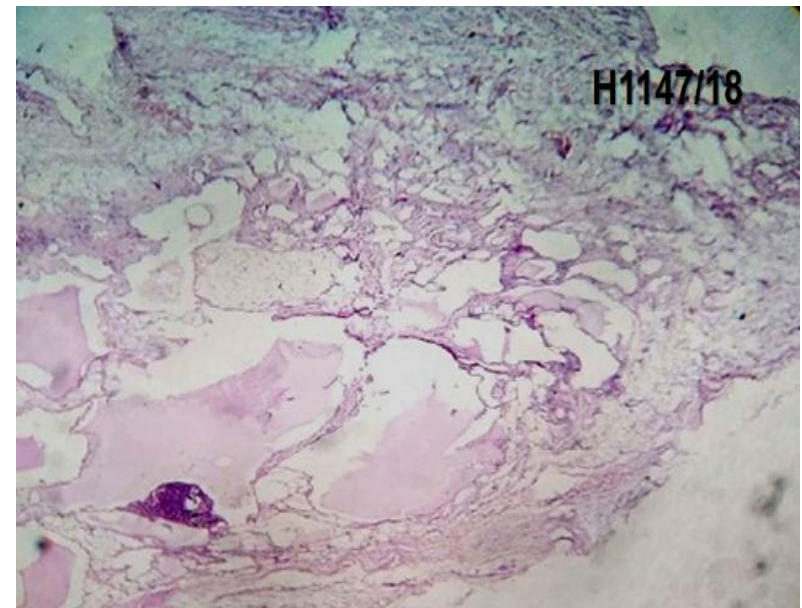

Figure 5: Low power view, $10 \mathrm{X}, \mathrm{H} \& \mathrm{E}$ showing multiple cyst lined by flattened epithelium

\section{Discussion}

Thymic cysts are classified into, congenital and acquired. A congenital thymic cyst is composed of unilocular cyst with a flimsy translucent wall. Thymic tissues adhering to the cyst wall is often

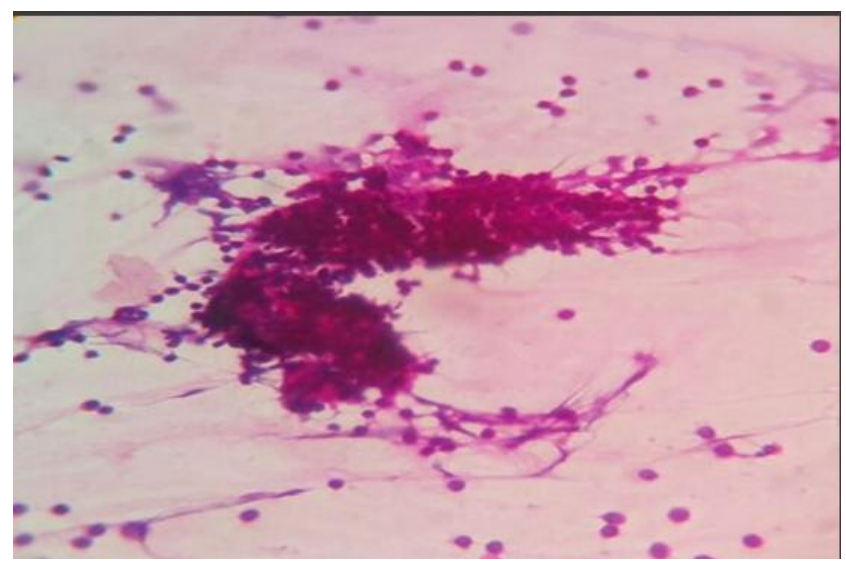

Figure 2: Scanner view, 4X, Giemsa, lymphocytes \& epithelial cells in pink protienaceous background

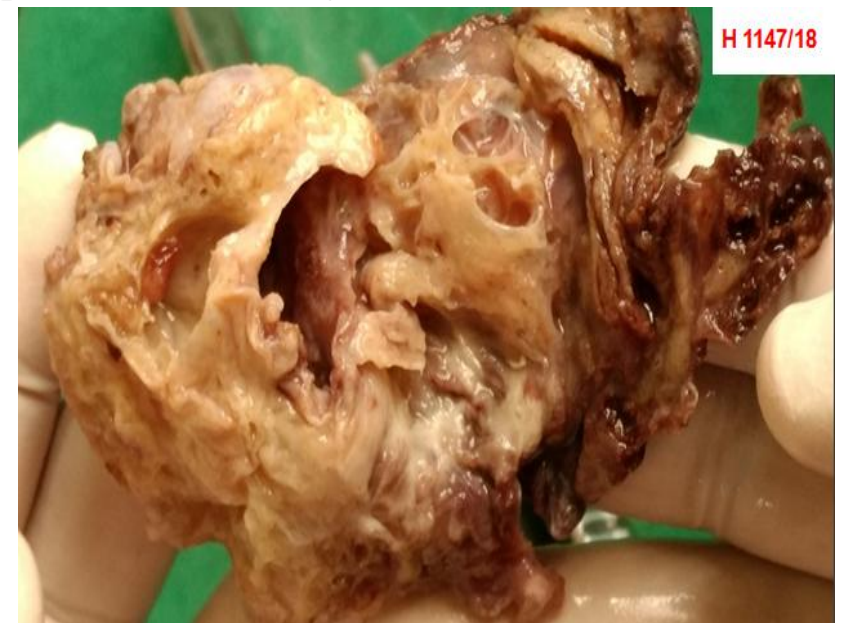

Figure 4: Gross-Cut surface showing multiple cysts filled with grey brown fluid

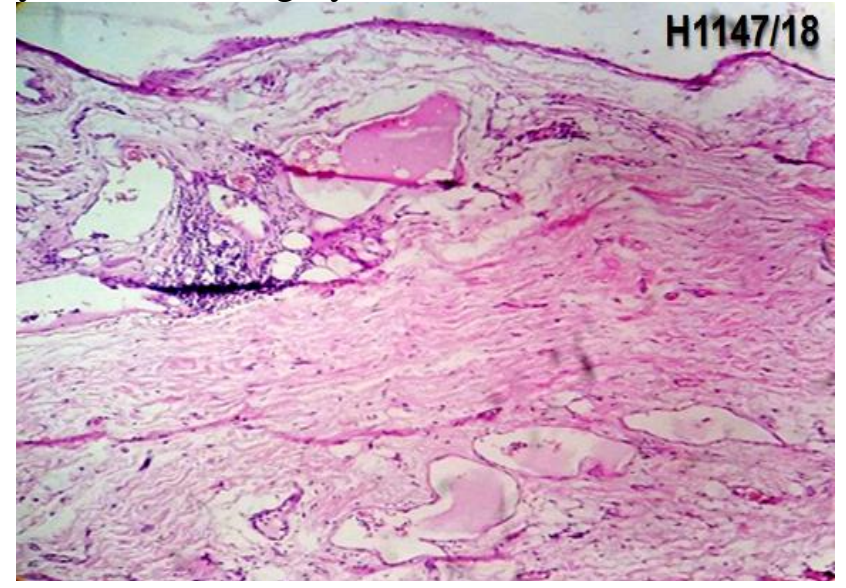

Figure 6: High power view, $40 \mathrm{X}, \mathrm{H} \& \mathrm{E}$ showing cyst wall

atropied without inflammation. The cyst is filled with serous fluid which is derived from persistent thymopharyngeal duct.

But, acquired thymic cyst comprises of thick walls multilocular cyst filled with murky fluid and is 
related to inflammation. A multilocular thymic cyst can occur at any age. Subsequent to acquired inflammatory process, it originates from dilatation of medullary duct epithelial structures involving Hassall's corpuscles. Reactive lymphoid hyperplasia with germinal centers formation is found frequently in the cysts, which implies that formation of multilocular

Thorough sampling of all thymic cysts should be performed in all cases because, some cases of multilocular thymic cysts are related to thymic neoplasms like thymoma and thymic carcinoma. This is done not only to establish correct diagnosis but also to rule out the neoplasm, particularly in cases where the cyst wall is partially thickened

\section{Conclusion}

In a case of mediastinal mass, always the possibility of thymic lesion should be considered, especially in this age group, even though it is a rare entity.

\section{References}

1. Strollo DC, Rosado de Christenson ML, Jett JR. Primary mediastinal tumors. Part 1. Tumors of the anterior mediastinum. Chest. 1997;112(2):511-22.

2. Suster, S. and J. Rosai Multilocularthymic cyst: an acquired reactive process : study of 18 cases. Am J Surg Pathol 1991. 15:388- 398.

3. Fujiwara T, Mizobuchi T, Noro M, Iwai N. Rapid enlargement of a mediastinal mass: thymoma hemorrhage into a thymic cyst. Gen Thorac Cardiovasc Surg 2008; 56:472-475.

4. Nomori H, Horio H, Suemasu K, Orikasa H, Yamazaki K, Nakano K. A case of rapidly enlarging unilocular thymic cyst. J Clin Pathol 2002; 55:636-637.

5. Saito Y, Murai K, Kawai Y, et al. Spontaneous hemorrhage of a thymic cyst in an adult: report of a case. Surg Today 2010; 40:958-962.
6. Fernando SR, Van Tornout F, Ball RY, Wimperis JZ. Spontaneous mediastinal haemorrhage linked with thymic carcinoma and myelodysplasia: a case report. Cases J 2009; 2:7821. 